This item was submitted to Loughborough's Research Repository by the author.

Items in Figshare are protected by copyright, with all rights reserved, unless otherwise indicated.

\title{
Extrinsic and intrinsic motivation for experience grounded tacit knowledge sharing in Chinese software organisations
}

PLEASE CITE THE PUBLISHED VERSION

https://doi.org/10.1108/JKM-03-2017-0101

\section{PUBLISHER}

(C) Emerald

\section{VERSION}

AM (Accepted Manuscript)

\section{PUBLISHER STATEMENT}

This work is made available according to the conditions of the Creative Commons Attribution-NonCommercialNoDerivatives 4.0 International (CC BY-NC-ND 4.0) licence. Full details of this licence are available at: https://creativecommons.org/licenses/by-nc-nd/4.0/

\section{LICENCE}

CC BY-NC-ND 4.0

\section{REPOSITORY RECORD}

Chen, Hui, Miguel Baptista Nunes, Gillian Ragsdell, and Xiaomi An. 2019. "Extrinsic and Intrinsic Motivation for Experience Grounded Tacit Knowledge Sharing in Chinese Software Organisations”. figshare. https://hdl.handle.net/2134/26698. 


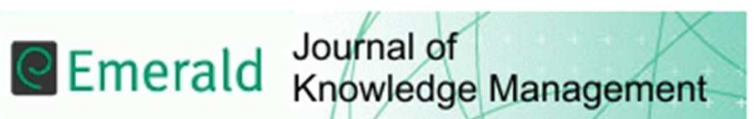

Extrinsic and Intrinsic Motivation for Experience Grounded Tacit Knowledge Sharing in Chinese Software Organisations

\begin{tabular}{|r|l|}
\hline Journal: & Journal of Knowledge Management \\
\hline Manuscript ID & JKM-03-2017-0101.R1 \\
\hline Manuscript Type: & Research Paper \\
\hline Keywords: & $\begin{array}{l}\text { Tacit knowledge, Knowledge sharing, Awareness and motivation, Chinese } \\
\text { software organisations, Software development process }\end{array}$ \\
\hline \multicolumn{2}{|c}{} \\
\hline
\end{tabular}

SCHOLARONE ${ }^{m}$

Manuscripts 


\section{Introduction}

Knowledge, as a unique and valuable resource, has played a significant role in allowing organisations to improve their competitive advantage (Gao et al., 2008; Amalia and Nugroho, 2011). Specifically, when shifting into the current knowledge-based economy age, managing knowledge represents a complex and crucial challenge for organisations and respective management activities (Drucker, 1992; Amalia and Nugroho, 2011). Knowledge, described as "actionable information", improves decision making and enhances the effectiveness of business actions and organisational creativity, and therefore strengthens companies' competitive advantage (Jashapara, 2004, p.16). The characteristics of knowledge are complex, dynamic and highly dependent of individual knowledge construction processes. This makes knowledge, especially tacit knowledge, difficult to capture, represent and maintain by organisations (Nonaka et al., 2000). Bhatt (2002) claimed that only a small part of the knowledge used in business processes is held by the organisation, the other part is internalized by the individuals. Consequently, Nunes et al. (2006) stressed the significance of the loss of knowledge assets when knowledgeable employees leave. Therefore, knowledge management (KM) and knowledge sharing (KS) are crucial in retaining valuable knowledge assets and in strengthening the ability of organisations to compete in an increasingly complex, dynamic and knowledge dependent global business environment.

The basic purpose of KM is creating and sharing knowledge in organisations in both explicit and tacit formats (Renzl et al., 2005). Explicit knowledge is expressed and codified in language, data, memos, instruction manuals, reports, standard operating procedures, documents, database and records (Koskinen, 2003; Awad and Ghaziri, 2004, p.47). Explicit knowledge is often equated with information and seen as an externalised and codified type of knowledge that can be processed, transferred and shared from individual to individual, and from organisation to organisation. Conversely, tacit knowledge - a term that was first coined by Polanyi (1958) - refers to hidden, non-verbalised, intuitive and unarticulated knowledge (Cavusgil et al., 2003). More pragmatically, tacit knowledge can be understood as experience that is embedded in an individual's mind (such as perspectives and inferential knowledge). Tacit knowledge "includes insights, hunches, intuitions, and skills that are highly personal and difficult to formalize, and as a result are hard to communicate or share with others" (Nunes et al., 2006). This type of knowledge is therefore not only the most difficult to share and keep in organisations, it is also rightly perceived to be the most valuable knowledge asset due to its contextualised and experience based nature. Meaningful KS processes in organisations need to be much more than mere information dissemination exercises and consider tacit knowledge sharing as a crucial component.

This paper focuses on $\mathrm{KS}$ as one of the fundamental aspects of $\mathrm{KM}$ and is widely acknowledged as an effective strategy to build competitive advantage in all types of organisations (McEvily et al., 2000). This assumption is based on an equally generalised perception that appropriate processes of KS, based on good practices of knowledge creation, storage, transfer and utilisation, are fundamental to resolving both strategical and operational problems in organisations and can dramatically improve the quality of products, services and internal processes (Abidi, 2007; Zhou and Nunes, 2012). For the purpose of this research, KS encompasses all the interactive activities related with transferring or disseminating knowledge between individuals, groups, and even organisations (Chen, 2015). Nevertheless, and despite a number of theoretical propositions, there is still a clear lack of effective implementation strategies and models to facilitate the tacit into explicit transformation that is required to 
support KS in the real world of practice (Chen et al., 2009). Despite its rather early identification (Rodhain, 1999), this translation of theory into practice is still recognized as one of the fundamental and key issues in the success of KS application in organisations (Jimes and Lucardie, 2003, Chen et al., 2009). Furthermore, there is a lack of understanding of why professionals of all areas of industry, and in the SW industry in particular, are so resistant to formal processes required for structured and systematic organisational KS.

\section{Summary of literature review}

The role of the literature in this type of inductive approach is one of theoretical sensitisation aiming to gain a general understanding of the main theoretical concepts in the area of study (Strauss and Corbin, 1998). The rationale behind the identification of these generic core concepts is: on one hand to guide the design of the semi-structured interview script and avoid reinventing the wheel, and to avoid inserting theoretical bias on the other (Zhou and Nunes, 2016). This follows propositions by Glaser and Strauss (2009), that defend that literature review in GT - theoretical sensitisation - should focus on the general theoretical area of the study but not become either systematic or critical, so as not to introduce theoretical bias in the study. Therefore, the review of literature in this study focused on gaining a general understanding on the core theoretical concepts in tacit knowledge, experience and KS.

"There is no need to review all the literature in the field beforehand, as is frequently done by analysts using other research approaches" (Strauss and Corbin, 1998, p. 49).

This is very different from traditional deductive approaches or even from Charmazian Grounded Theory where a literature review is used as data and influences the analysis, but it is the common practice with traditional inductive approaches, such as the one chosen for this study. However as it pointed out by Evers and $\mathrm{Wu}$ (2006) in construing grounded theory as a methodology in opposition to hypothesis testing there is fundamental tension between the individual's values and beliefs and the role of what is expected to be emergent and grounded theory. Very early on Glaser and Strauss (1967) realised this by stating that: "of course, the researcher does not approach reality as a tabula rasa" (Glaser and Strauss, 1967, p. 3). Researchers will have a perspective that will help him see relevant data and abstract significant categories from his scrutiny of the data. Therefore, Strauss and Corbin (1998) suggest that:

"Although some analysts claim to be able to 'bracket' their beliefs and perspectives toward data, we have found that doing so is easier said than done. We know that we never can be completely free of our biases, for so many are unconscious and part of our culture inheritances. We found it more helpful to acknowledge that these influence our thinking and then look for ways in which to break through or move beyond them." (Strauss and Corbin, 1998, p. 99)

Furthermore, Strauss and Corbin (1998) suggest that the increase of theoretical sensitivity helps the user recognise bias and help the researcher "overcome analytical blocks" (Strauss and Corbin, 1998, p. 88). Since the onus of making perspectives and biases lies on the research team, it is important at this time to express that the research presented in this paper began with an initial assumption that understanding professional's awareness and motivation for KS may be the key for the much-needed translation of KM and KS theories into practice. 
This assumption was moderated by the theoretical sensitisation effort and resulted in the research question presented below.

\section{Tacit knowledge and experience}

The philosopher Polanyi (1958) was the first one who advocated that human knowledge has a dimension other than the usually acknowledged explicit knowledge - tacit knowledge. $\mathrm{He}$ related this type of non-easily represented knowledge to individuals' own experiences and personal senses. His most telling statement is probably his simplest in defining tacit knowledge: "we know more than we can tell" (Polanyi, 1966, p.4). This points to the essence of understanding and distinguishes it from the externalisation of that understanding. Therefore, tacit knowledge is unformulated, personal, resulting from human activity and experience, and importantly, difficult to transfer. Berman et al. (2002) confirmed this view of tacit knowledge as subjective, difficult to formalize and related to values, ideas, emotions and experiences. Gourlay (2006) claims that the concept of tacit knowledge "is underspecified, and carries too many meanings, that we only have a nascent understanding of it, that it resists operationalization". This type of argumentation led Wilson (2002) to state that it is not possible to manage this type of knowledge, which is held mostly in people's own minds. Wilson's position is that in this case, knowledge that resides exclusively in human's mind can never be externalized.

On the contrary, Nonaka and Takeuchi (1995) had previously defended that this externalisation is not only possible, but also desirable. They described tacit knowledge from an organizational management perspective in order to apply it to knowledge-creating processes in organisations. Tacit knowledge represents the experience from the individual, expressions of dynamic human actions from "evaluation, attitude, point of view, commitments and emotion" (Pathirage et al., 2007, p.116). Since tacit knowledge is related to the individual and dynamic human processes, it is hard to capture, represent and maintain by the organisation. However, most practitioners and academics believe that the most valuable knowledge assets are embedded in tacit form; developed and internally constructed by the individual (Bhatt, 2002; Mooradian, 2005). Therefore, in traditional KM schools tacit knowledge must firstly be converted into explicit knowledge before it can be managed (Nonaka and Takeuchi, 1995; Nonaka et al., 2000). However, Brown and Duguid (1998) warned against a simplistic view of translation by proposing that tacit knowledge has many complex characteristics which make the total and absolute conversion into explicit or documented instruments difficult and complex.

In this sense, and when strictly associating tacit knowledge with experience, the distinction between individual/collective dimensions of tacit knowledge made by Gourlay (2002) does not apply. In this research we are interested in the knowledge that results from engaging with organisational activities and is acquired through individuals sensory and qualitative experience of actually doing something (Gourlay, 2001) and not a the kind of knowledge that results from philosophical thinking or conceptual discussions. It is well accepted that the presence of others (peers as well as senior colleagues and mentors) is generally regarded as essential for the acquisition of tacit knowledge (Gourlay, 2006), but the cognitive process that results in tacit knowledge is an individual one. Therefore and according to Polanyi (1958) full descriptions of the activities can be made by the individual, including both subsidiary elements and relations between them. Accordingly, most theoretical propositions on tacit KS accept that the key for the operationalisation of KS in organisations lies in recognising that tacit knowledge is practical in nature (Sternberg, 1994), is closely associated with work 
processes (Ambrosini and Bowman, 2001), consists of technical and professional specific skills ("the kind of informal, hard-to-pin down skills captured in the term "know-how" (Nonaka, 1991)) and therefore is closely associated with experience (Nonaka, 1994; Lam, 2000).

However, "fundamental to the in-depth exploration of tacit knowledge is the need for greater clarity of its significance and application in certain knowledge management domains" (Venkitachalam and Busch, 2012). The study reported in this paper aimed at studying the knowledge sharing of experience-based and externalized tacit knowledge in the SW sector in China.

\section{Knowledge sharing}

Knowledge sharing is an essential process and potentially the most important activity in knowledge management (Davenport and Prusak, 1998; Ryu et al., 2003). It can be simply be expressed as the organisational processes associated with making knowledge available to others (Ipe, 2004). Exploring this concept of 'others' further led Lee (2001) to propose that knowledge sharing is the activity of transferring or disseminating knowledge between individuals, groups, and organisations. Al-Hawamdeh $(2003$, p.81) further elaborates this point by stating that "knowledge sharing, in its broadest sense, refers to the communication of all types of knowledge, which includes explicit knowledge or information, the 'know-how' and 'know-who' which are types of knowledge that can be documented and captured as information" as well as less well defined and structured knowledge such as skills and competencies.

However, this process of knowledge sharing is also linked with inherent aspects of organisational life such as organisational behaviour and culture. As proposed by Lin (2007, p.315), knowledge sharing results from "a social interaction culture, involving the exchange of employee knowledge, experiences, and skills through the whole department or organization". Therefore, the culture of an organisation is one of the major factors in people's attitude towards sharing and disseminating knowledge (Ardichvili et al., 2006; Suppiah and Sandhu, 2011). Furthermore, due to the individual and at times informal nature of knowledge sharing, managers often lack critical information about how employees share knowledge, communicate with each other or more generally how they spend their days and how they feel about their peers (Krackhardt and Hanson, 1993). Moreover, Krackhardt and Hanson (1993) state that "managers simply can't be everywhere at once, nor can they read people's minds", therefore they may have difficulties in establishing the right type of culture and organisational structures that are required by KS processes. Additionally, knowledge sharing happens between individuals or groups (Awad and Ghaziri, 2004), and therefore is highly dependent on the individual's willingness to represent and exchange their experiences, practices and other forms of tacit knowledge (Nonaka 1994).

$\mathrm{KS}$ is therefore closely dependent on interpersonal interactions at the conscious level stimulate and KS strategies should aim to enhance these interactions, sharing activities and interplay among individuals (Leonard and Sensiper, 1998). However, KS should not only be seen as a way to help colleagues to improve their job performance, but also a strategy for an organisation to manage efficiently and effectively difficult aspects of organisational life, such as high turnover of staff, fast evolution of technologies or constant changes in socio-technical environments. 
Finally, it is important to highlight that the processes of KS are closely related with availability and adoption of particular technological solutions. For instance, the recently emerged and now widely adopted social media and networks have a "more collaborative, interactive and dynamic nature" and therefore afford improved sharing of knowledge (Patrick and Dostsika, 2007, p.400). Numerous strategies have been developed in order to implement KS in organisations, namely in the SW sector as discussed by Chen et al. (2012). Therefore, in order to facilitate knowledge sharing, it is critical to consider the interactions between the organisation, the individual and the technology (see Table 1).

Table 1. Main impacting factors on knowledge sharing

\begin{tabular}{|l|l|l|}
\hline \multicolumn{1}{|c|}{ Factors } & \multicolumn{1}{|c|}{ Description } & \multicolumn{1}{c|}{ Related Literatures } \\
\hline Organisation & $\begin{array}{l}\text { Business mission; } \\
\text { Organizational culture; } \\
\text { Supporting from senior management. }\end{array}$ & $\begin{array}{l}\text { Jager (1999), Sackmann and } \\
\text { Friesl (2007), Reige (2005), } \\
\text { Reige (2007) }\end{array}$ \\
\hline Individual & $\begin{array}{l}\text { Common identity; } \\
\text { Willingness to share knowledge; } \\
\text { Agreement and collaboration between } \\
\text { different departments. }\end{array}$ & $\begin{array}{l}\text { Davenport and Prusak (1998), } \\
\text { Cabrera and Cabrera (2002) }\end{array}$ \\
\hline Technology & $\begin{array}{l}\text { Personal or organizational networks; } \\
\text { High-tech support. }\end{array}$ & $\begin{array}{l}\text { Davenport and Prusak (1998), } \\
\text { Hansen (1999) }\end{array}$ \\
\hline
\end{tabular}

However, the success of these KS strategies, such as storytelling, Q\&A, specialised discussion fori or even mentoring programs are highly dependent on participation of the more experienced practitioners. The participation and willingness to sharing knowledge has become one of the most complex problems to be addressed by organizations (Cabrera and Cabrera, 2002; Chen et al., 2012). If individuals who possess tacit knowledge that is important to the organisation are either "actively discouraged" from sharing or "censor" themselves, none of the benefits suggested above can be realized (Leonard and Sensiper, 1998). Therefore, the inherent complexity associated with understanding, encouraging and nurturing motivation and willingness to share knowledge, needs to be addressed by going beyond the established, repetitive and hitherto not very successful claims for top management support, KM champion nominations and explicit HR financial and promotion schemes. This paper proposes that motivation for participation in KS initiatives emerges from a professional and individual awareness of the intrinsic value of KS itself.

\section{Research design and approach}

\section{Research context}

The software industry sector was identified as an ideal context for the research reported in this paper since, as claimed by Fagri et al. (2010), software design and development requires a collaborative and knowledge-intensive team approach that depends greatly on the experience of the individuals involved, such as analysts and programmers. The nature of the software industry as a knowledge-intensive industry (Dingsoyr, 2002) makes it particularly relevant, since successful KS implementation can significantly improve the collaborative processes of SW development, training and knowledge retaining. In particular, well implemented and efficient KS practices can support SW companies in facing changeable business environments, enable transitions to new and constantly emergent technologies as 
well as the very high personnel turnovers that characterise the sector (Dingsoyr, 2002; Mishra and Bhaskar, 2011). Furthermore, as claimed by Fagri et al. (2010), software companies require collaborative and knowledge-intensive work that depends greatly on the experience of their individuals. Therefore, from a theoretical perspective, this sector seemed ideal for this study.

Furthermore, this context seems to be highly adequate since, according to Edwards (2003), there is an active community of practice in SW industry where KS seems not only to be common practice but lies at the basis of collectively problem solving and error debugging. What is interesting is that much of their KS and cooperative work is distanced from the eyes of knowledge management mainstream communities. Therefore, from both practical and theoretical perspectives, this sector seems ideal for this study. The study itself aims to investigate, identify, characterise and express what types of professional experience are acquired in daily working practices of the software development process, so that they can then later be externalised as explicit knowledge, stored and exploited through the use of information technology structured approaches.

Since, the research team is mostly located at Chinese universities a multi-case approach in the Chinese sector was adopted. The Ministry of Industry and Information Technology (MIIT) of the People's Republic of China has published that the revenue of China's software industry reached \$23.8 billion in July 2011 (Yang 2011). IBIS World, a leading American industry research firm, has also analysed the SW development industry in China and concluded that it has grown by $25 \%$ of average annual rate from 2011 , and is expected to achieve revenues of more than $\$ 868$ billion in 2016 (Taft 2012). This high growth rate will make China the fastest-growing software industry in the world, and thus, the Chinese software industry will take an increasingly important role in the global software market. Therefore, the Chinese SW industry context is particularly meaningful and makes the study of interest to international audiences as well as national ones.

\section{Research question}

The research project reported in this paper is driven by the general aim of exploring and understanding SW professional's awareness of the benefits and motivation for KS. It is expected that this understanding will be useful in providing a practice-based view of tacit knowledge sharing in this type of organizations. In order to explore this aim in depth, a multi-case approach in the Chinese sector was adopted. This multi-case study approach was influenced and shaped by following the research question:

What are the factors influencing motivation for experience-based externalised tacit knowledge sharing $(K S)$ in the world of practice the software industry in China?

The research design, developed to respond to the above research question, combined a multi case-study approach with a grounded theory (GT) inductive qualitative approach for data collection and analysis. 


\section{Case-studies}

The fieldwork was conducted in the SW sector in China using three types of companies that are representative of the fabric of the sector, namely a small and medium-sized private enterprise (SME), a large state-owned enterprise (SOE) and a large private company.

The SME company is named BAIDUCHUAN Information Technology Co., Ltd.; and is a multimedia software research and development company, founded in September 2010 in Xiamen City (Fujian Province, South of China). The second company is a state-owned company named Yirong Info Co., Ltd., founded in 2002. It is an innovative enterprise fully owned and controlled by Great Power Science and Technology Co., Ltd (GPST) which is a company that provides IT support services, including the design, development and maintenance of the information systems for the national State Grid of China. Finally, the third company is a private company named UNIS Archives (Bosi at the time of the research), which mainly designs and develops electronic archives systems as well as providing the professional consulting for digitalisation of archives.

\section{Data collection and analysis}

This study used Grounded Theory (GT) as an inductive methodology to collect, analyse and interpret data from the case-studies. GT was originally presented by Glaser and Strauss (1967), who proposed a process for conducting inductive and qualitative research framed by clear analytic and systematic guidelines. It advocates that inductive theory can be generated from qualitative data collected within particular social contexts and informed directly from participants in the phenomenon being studied, without the bias of preconceived theoretical frameworks. GT has been proven to be very appropriate and highly used in KM research as well as in IS/IT research (e.g. Hunter et al., 2005; Pauleen et al., 2007; Zhou and Nunes, 2012). It has been specifically recommended for use in the SW industry as it enables the investigation, analysis and explanation of "the socio-technical issues in software development" (Lings and Lundell, 2005, p.197).

Semi-structured interviews were designed as the data collection technique to gather in-depth data to respond to the research question. The structure was constructed by following the SW development process discussed in Figure 1. Interview questions themselves were open-ended in order to enable the researcher to focus on the more significant questions and to elicit substantial perspectives, opinions and ideas from the interviewees. All questions were originally developed in English and then translated into Chinese. The English questions aimed at allowing discussion of structure and design among the predominantly English research team. Prior to the interview, each interviewee received introductory information about the purpose of the study and information on research ethics issues like confidentiality and anonymity.

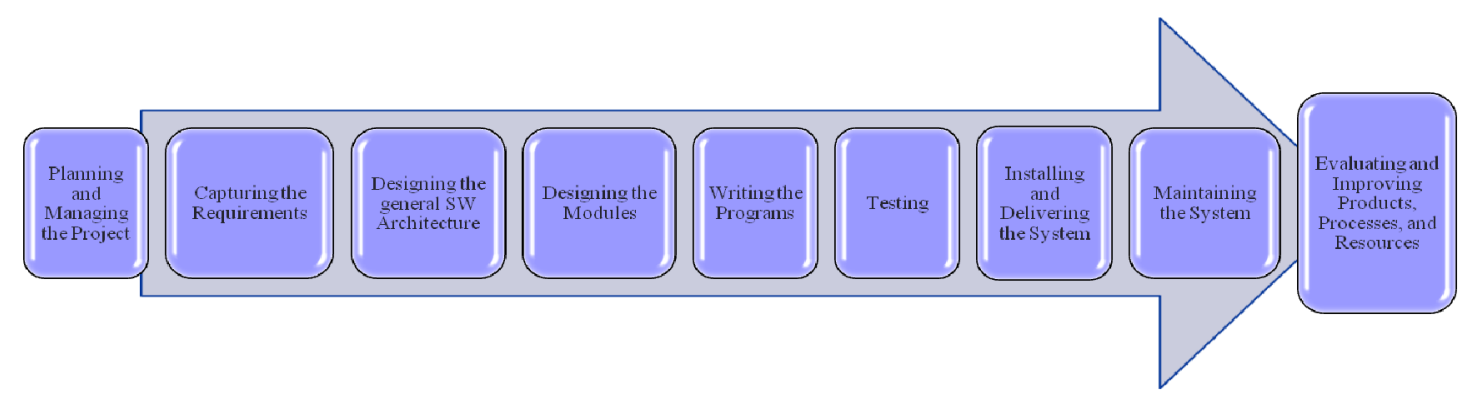

Figure 1. Main Operational and Management Activities as Identified for Interview Script 
Overall, there were 44 participants. The sampling was devised so that informants from all areas of the SW development in the company were represented, namely: 1 share-holder, 5 managers, 11 project managers, $25 \mathrm{SW}$ developers, 1 human resource manager and 1 salesman. A detailed biographical profile of all the participants is provided in Appendix.

All interviews were conducted in Mandarin Chinese, digitally recorded and then transcribed and codified. The data analysis followed a Straussian pattern of coding, which consists of a recursive process of open coding, axial coding, and selective coding:

- Open coding represents the "analytic process through which concepts are identified and their properties and dimensions are discovered in data" (Strauss and Corbin, 1998, p.101). In practical terms, it is used to break data into fragments, "compare incident with incident, name apparent phenomena or emerging patterns and begin the process of comparison between the codes identified" (Birks and Mills, 2011, p.95). Therefore, in this step, early conceptualisations can be identified and categories and sub-categories discovered.

- Axial coding follows the initial open coding and is considered as the "process of relating categories to their subcategories" (Strauss and Corbin, 1998, p.123). It attempts to develop and delineate the linkages between categories and subcategories around the axis of a category (Mansourian, 2006).

- Selective coding is the process of "integrating and refining the theory" (Strauss and Corbin, 1998, p.143). In practical application, "the major categories are finally integrated to form a larger theoretical scheme in which the research findings take the form of theory" (Strauss and Corbin, 1998, p.143). Therefore, it is the ultimate step which grounds the basis of the theory.

The qualitative data analysis software NVivo was used to enable the researchers to read, retrieve, analyse and manage the data from the interview transcripts. NVivo was also used to support open coding and group the codes into a hierarchical category structure that formed the final theory (see Figure 2).

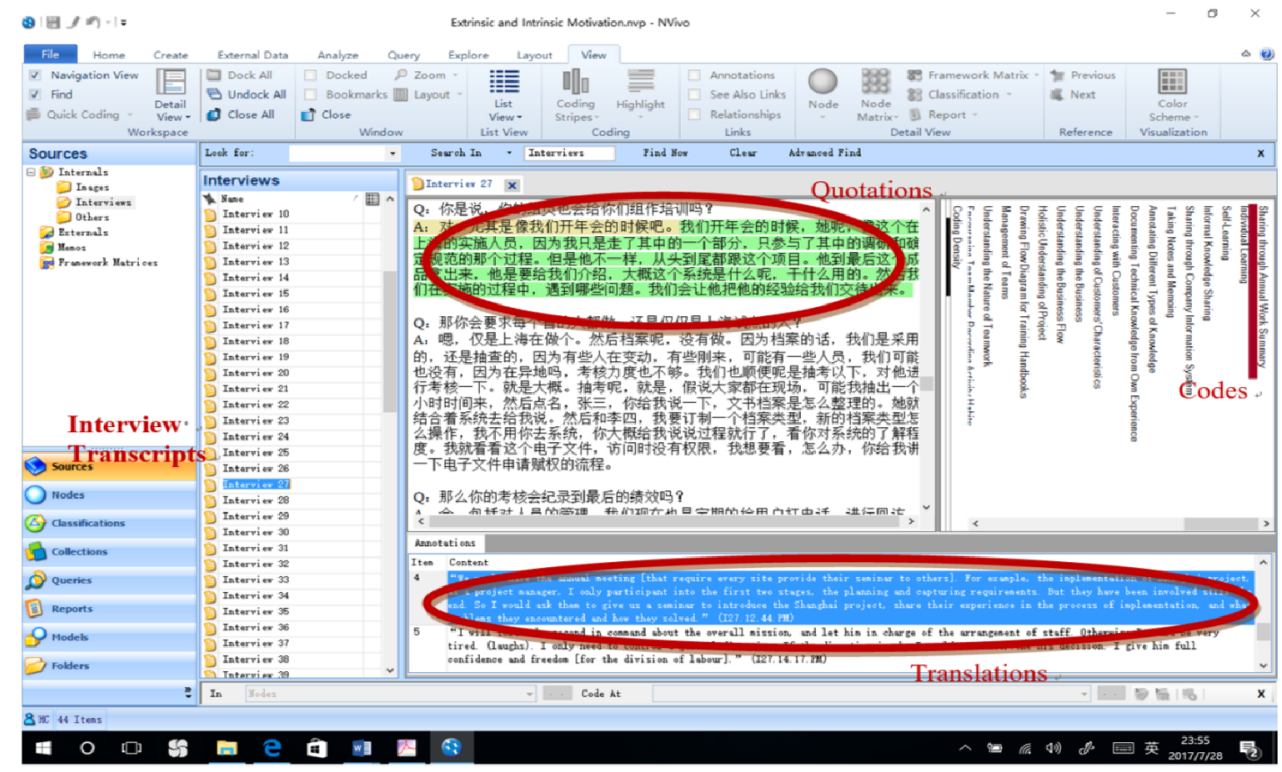

Figure 2. A Screen shot of NVivo Coding Process 
All the interviewees' opinions presented in the theoretical narrative that is presented here; first in the Findings section and then in the Discussion section were anonymised using the following scheme: I + Interview Number. Page Number. Line Number. Participant's Role in the Company. This unique identifier allows the researcher to anonymise and protect the identity of the participants, but also to provide evidence for the categories and subcategories that form the theory proposed.

\section{Research findings}

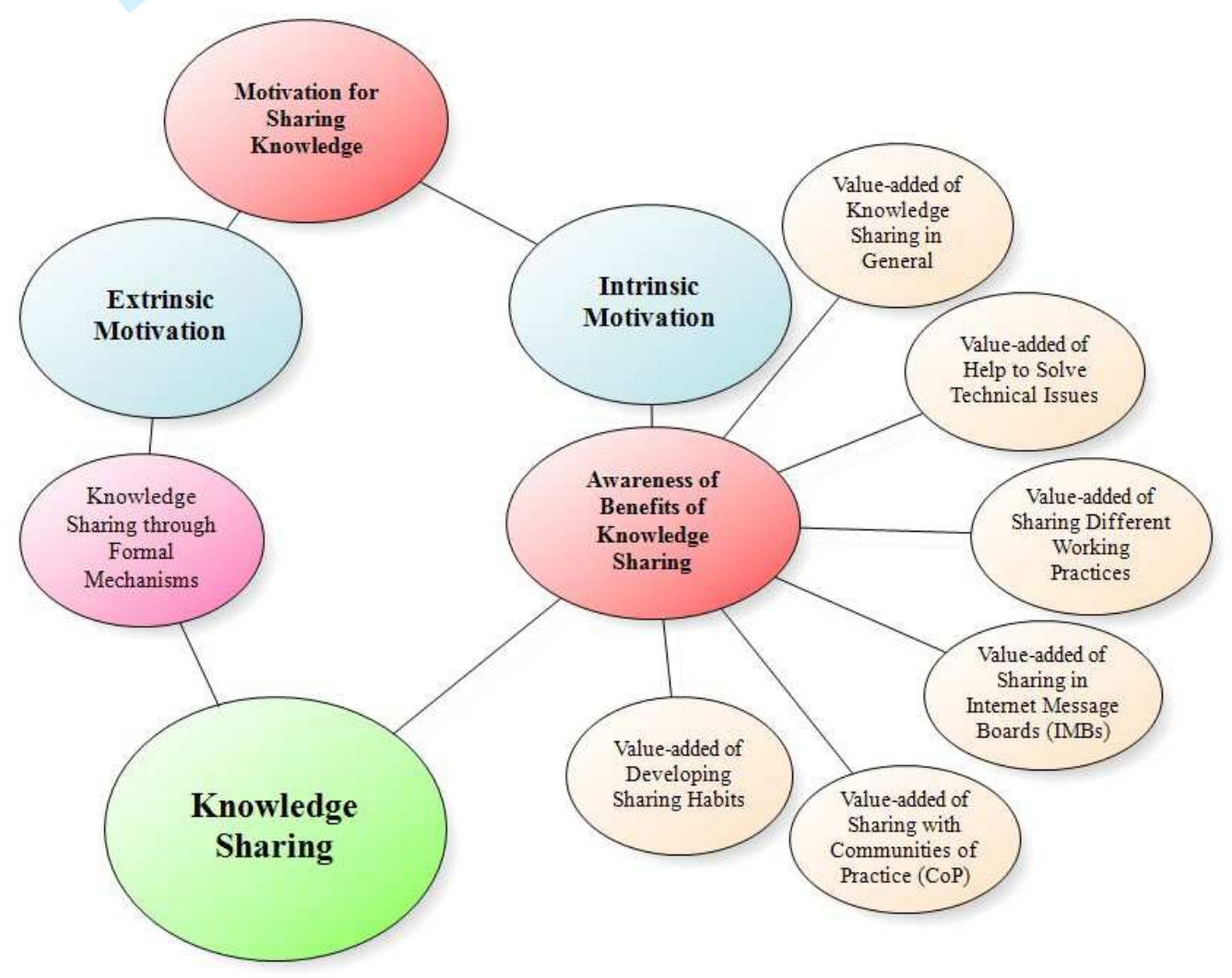

Figure 3. Motivation for Knowledge Sharing from Extrinsic and Intrinsic Factors.

This research confirmed some of the existing theoretical proposition in KS presented in Table 1 , but also revealed some interesting new insights. Knowledge sharing through formal mechanisms and well known organisational structures and policies did emerge as one of the important aspects of KS as an Extrinsic Motivation. However, a whole and very interesting category associated with Awareness of the benefits of $\mathrm{KS}$ emerged as an fundamental Intrinsic Motivation (Figure 3). This section of Findings will provide a descriptive and explanatory theoretical narrative of these categories. The Discussion section will then provide an integrative and holistic discussion. 


\section{Extrinsic motivation}

Extrinsic factors are related to formal mechanisms offered or imposed by the organisation, groups of professionals or even blogs and discussion fori. These are really just confirmatory findings that resulted in 5 sub-categories and 20 high-level codes, as shown in Figure 4.

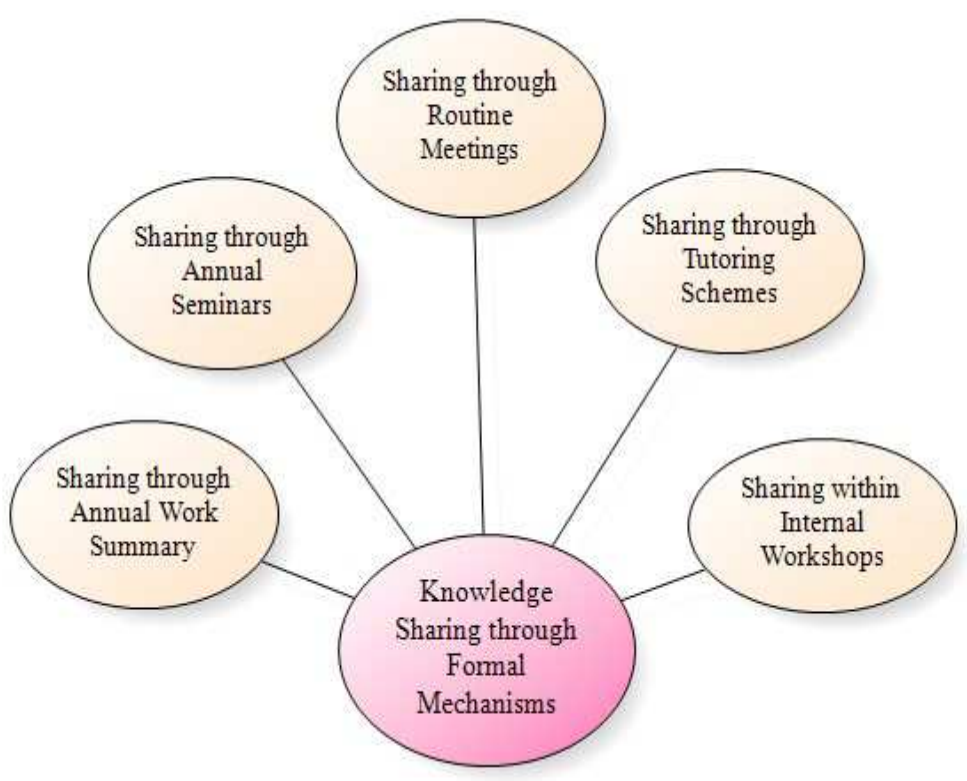

Figure 4. Extrinsic Motivation: Knowledge Sharing through Formal Mechanisms

Formal mechanisms for KS were defined in this research as non-optional processes that are part of organisational policies. These may range from formal meetings to the production of mandatory review documents which are common at the end of SW projects.

The end of the year personal report was mentioned by employees and managers from both Yirong and Bosi. It is produced annually and requires employees to make a self-summary of their work and self-evaluation of their performance. These documents are then made available internally in these companies through "collaborative systems" (I27.11.15.PM) that, although technically different in the two companies, have the aim of allowing the sharing of experiences and work practices among all employees. One of the project managers illustrated how he used the chance afforded by having to do this document to reflect on his experience, externalise it in a document and then share this explicit knowledge with his colleagues:

"I have shared [my experience with colleagues] through the annual report of work in the company. In the report, I write the real story and practical experience I gained though the year ... not just something copied from the Internet. The knowledge that I have now written down comes from my insights [of working in customers' implementation sites], and this was the only opportunity that I had and the only time I was given to recall my memory on my working practice and reflect upon it ... and also ... that I had the courage to write it down." (I10.4.4.PM)

A less formal but still mandatory annual means of sharing ideas, emerges from the annual company retreat. This is a highly anticipated reunion away from the workplace and usually 
Apart from these annual seminars that were seen as ideal mechanisms for knowledge sharing, there are more frequent "weekly meetings" (I6.5.6.D), routine meetings that were often considered as a way to summarize and discuss the week's work, present employees' problems and "exchange or share experience" with others (I6.5.6.D). Not surprisingly these meetings were strongly valued by project managers:

"Some people are not particularly good at communication, and always hide their own ideas in their own stomach [idiomatic expression]. However, they have come to realise that if they cannot resolve a technical problem, others may, so we started to use these routine meetings to force everyone to talk. If there was no such meeting, everyone would do their job and keep to their own mind. Sometimes, such problems can still be unresolved for a while. That means during those periods, he achieves nothing. It is really a waste of time. ... [Sighs] ... So I strongly impose these meetings to help deal with the problems that they cannot deal with themselves." (I18.2.33.PM)

Tutoring Schemes were also seen as an excellent means of sharing knowledge. Even though the company's training handbook would show all the information that newcomers needed to know to start their work, all of the companies studied still provide a personal tutor for each new member of staff. These tutoring schemes are a way for senior experts (known and addressed by junior employees as "shifu", a word that in other contexts could mean master or

in a good rural hotel. This is common practice in Chinese organisations of all sizes and usually occurs just before the Spring Festival holiday. This retreat usually takes two to three days that are divided into reflection meetings in the morning, social or sport activities in the afternoon and entertainment in the evenings. For the purpose of this research these retreats are named as "Annual Seminars" since they were referred as such by the informants. The reflection sessions in the morning are seen as particularly useful and one of the few occasions in which employees are given an opportunity to speak freely in extremely hierarchical Chinese organisational settings. Furthermore, these sessions are intentionally interdepartmental and include elements from all areas of the organisation. Therefore, once a year individuals are given an opportunity to voice their ideas, complaints and opinions, as "Ah ... knowledge sharing in our company is ok. Sometimes, when New Year is coming, our job would be relatively less than before. The boss would organize some seminars ... and ask us to talk and share our own experience with others." "Right ... especially the annual seminar was very useful for sharing knowledge. For example, about the Shanghai project. As a project manager, I may only requirement specification in the beginning. However, the installation expert, who is staying at the Shanghai customers' site, was with the project from start to finish. He probably was the only one who could reflect holistically on all of the practical experience, working processes, and problems encountered for this project. The annual seminars require staff to fly back to headquarters [Beijng and, in this case], and gave us a chance to listen to his story about Shanghai. Therefore, as a manager, I could ask him to share his experience and explain some questions for installation experts in other provinces." (I27.12.44.PM) 
teacher) to share their experience with their junior colleagues, as explained by one of developers:

"Generally speaking, our developers are willing to share ideas. Sometimes, I am even afraid that I might talk too much ... so much that newcomers may absorb it. I would tell him everything. If I have time, I will definitely teach him 'hands to hands' [idiomatic expression] ... It will be very good for our teamwork." (I14.3.22.D)

Informants of all the companies also added an additional mechanism described as "internal workshops" (I27.6.17.PM). These occasional workshops are led by internal experts. These sessions occur several times a year, whenever the need emerges for a particular area of expertise to be shared.

"Sometimes our developers will organize the internal self-training workshops which imply one of our own giving a lecture on his specific strengths and sharing with others." (I16.2.21.D)

Additionally, it was stressed by several project managers that these workshops are not necessarily aimed at newcomers, but are very often targeted at others employees who may lack expertise in specialized subjects:

"The internal workshops provide a chance for people to express their strengths, and more importantly, to summarize their own experience. For myself, I started as a very unexperienced installation staff member... through a lot of learning, work and trouble I am now a senior expert. Therefore, following my own experience, new employees and employees who never experience either specific project types or technologies, have everything to gain from the internal workshops. It is a fast way to make them more capable." (I27.6.18.PM)

The vast majority of the formal mechanisms for KS presented here, are not particularly innovative and have been part of KS good practice in organisations for some time now. The instantiation and implementation of these mechanisms is of course strongly influenced by the Chinese culture, but management motivation for and use of these KS mechanisms seems to mirror both academic theorization and practice globally. Therefore, the use of these findings is more of a confirmatory nature.

\section{Intrinsic motivation}

Intrinsic factors are very interesting findings from this study, and concentrate on the core category that emerged within Intrinsic Motivation: Awareness of Benefits of Knowledge Sharing. 
Evidence of placing Awareness of Benefits of Knowledge Sharing at the core of the success of KS processes emerged very early in the analysis as a result of an informant's own definitions of $\mathrm{KS}$ as "a process of exchanging ideas and exchanging opinions, which can produce new knowledge" (I2.15.7.D). Moreover, KS with other experts and informed individuals was seen to enhance the individual's influence internally in the company and externally as well as to increase the perceived value of individual's knowledge itself. For instance, one of the developers used a metaphor to explain the value added during knowledge sharing:

"Well, sharing knowledge ... of course ... it is important. For example, when you play chess with a senior player, your skill will get better; if you play chess with a lower junior, your skill will only get worse. And if all the masters of chess players could talk to each other, and share some experience, then they could only gain more knowledge ... (smiles) ... this is the value-added of knowledge." (I15.6.19.D)

Knowledge sharing through working practice and day-to-day interaction with peers in the company is expected to help employees to solve similar technical issues that others have experienced before. For instance, one of the UNIS Archives company installation experts working in the Shanghai customer site claimed:

"Right, you cannot always look for your boss to solve the problem for you. Then I would communicate with other installation experts in other provinces through the private telephone, $Q Q$ or WeChat. The colleagues working at other provincial companies actually implemented the same system with same features. Some of my problems they might have encountered before. If they have solved them before... then through communication we could help each other." (I24.6.7.D)

This inclusive learning culture seems to help people not only to improve themselves but also realize their aspirations, as expressed by one of the project managers: "I am not a particularly strong person. It is possible to learn about some experiences from other successful project managers" (I18.6.25.PM). One of the developers illustrated this concept as follows: 
"First of all, the knowledge acquired through experience, it is not easy to get. This type of knowledge is very valuable, yes, because it is not possible to get it from books, especially because not everyone's working environment is the same, neither are the contexts and specific conditions of project processes. Therefore, the experience gained from the different projects can be totally different. Yes. So the experience a colleague gains from his project could be very distinctive from what I might get from my own project. " (I15.6.7.D)

However, all of the technical developers openly declared that not all knowledge sharing processes were internal to their organisations.

"Sharing outside the company is also definitely good. It is better that we have the opportunity to share the things with other people. The actual experience of the problem still belongs to you, but, if we share, all us [meaning all of us in the development community] can learn and improve our knowledge, and grow faster together." (I16.5.19.D)

Like SW developers all over the world, developers from all three companies studied actively seek to advice from the wider national and, at times, international community of practice that forms around Internet Messaging Systems, Bulletin Board System (BBS) or Professional Forums. These social media forums work based on informal and volunteer response to technical questions posed. Reaching a very wide audience and therefore allowing for very fast response times, these very simple and limited systems have been used by the SW development community for decades. This type of system would qualify as a community of practice $(\mathrm{CoP})$ in the modern sense of the term and, according to the respondents to this research, these social media forums are always the first port of call whenever technical problems emerge, often before asking in-house.

"I always use the Internet Forum to exchange ideas. That is, I would post a message into the 51Test [in order to seek for help]... Ahh, you may not know this, but the 51Test is a relatively large forum for questions and answers. The reasons I use this forum are: one, because the people are really enthusiastic and, two, because there is a lot of information sharing on this platform, particularly in the testing field. So I gain a lot from it." (I38.5.7.D)

51Testing (http://www.51testing.com/html/index.html) is the most popular testing forum for Chinese developers and testers. It stores a wealth of responses on how to fix SW bugs, develop test specifications and deal with unstable systems. This forum specialises on testing, but, there is a myriad of other such Internet Message Boards, both generic and specialised, in a variety of SW development areas, such as programming languages, configuration management and project management.

Despite its extremely high level of use and success, Internet Message Boards only provide very limited degrees of interaction and do not usually provide rich interaction. This interaction is perceived to be very important and is usually supported by more sophisticated Internet based CoPs, such as Zhihu (http://www.zhihu.com/), which is a Chinese community for questions and answers on different technical issues, that is public and open for everyone. 
"This type [sharing in the community] is more interactive, because you can hear different voices. Like a brainstorm ... you can see the different points of view."(I2.6.10.D)

This type of Community of Practice $(\mathrm{CoP})$ is recognised to be a mechanism of obtaining and providing knowledge from experience:

"This [sharing] is a process that we need to understand. When I joined this industry, I learned from my work by myself and did not share with others. But after a period of time, I found that I was wrong. I found that all the techniques I learned the hard way all by myself, I could have found on the web. This web is a big platform where everyone is sharing. For example, I have a new innovation, and you have another. Then each one of us only has one innovation. If we share with each other, both of us will have two innovations and both of us gain from each other. If I am selfish and you are selfish we both lose. " (I14.3.11.D)

Therefore, knowledge sharing should be seen as a process of cooperative growth and junior SW developers may not always understand it or be aware of its importance. Moreover, more traditional ways of knowledge acquisition such as their mentor, friends and professional networks (see Section 5.6.3) may not be enough to support their professional practices efficiently. CoPs were presented as the ideal platform to share and exchange ideas with others but require the awareness and willingness to develop personal knowledge sharing habits.

"I will always document [in a separate file in a folder he created for this effect] the information on the problem-solution that I found from the Internet. If I do not record this, it might still be a problem for me next time I need it because I may forget it. Moreover, if there is someone asking for help from communities on that problem for which I already know a solution for ... because I have it recorded ... I can then post it onto the site and answer their questions." (I9.8.20.D)

"In fact, sharing is a habit. Some people are good at writing, like blogging, they like to write down their technological knowledge in their blog, and share with others. Many are not so good or do not have the habit of doing so, but for sharing to work effectively we all need to make an effort and get used to share regularly." (I5.14.20.M)

This suggests that awareness of benefits of knowledge sharing and having the experience, understanding, habit and skills to maximise these benefits are the key for successful KS.

\section{Discussion}

The findings presented are very interesting in themselves, but also confirmed that the inductive approach adopted by using Grounded Theory seems to have been very successful. The emergent theory seems to be indeed grounded in the context of case-study rather than biased by the prevalent literature review. In this sense, the findings of this research are very different from those that would have emerged from a deductive approach (for instance a questionnaire based survey) that would either prove or disprove a priori defined theories deduced for the existing literature on the field. 
The findings showed that the motivation for knowledge sharing, a time consuming and demanding activity, is highly related to the awareness that managers and developers have of the benefits associated with this professional practice. Informants expressed that they shared their experiences and tacit knowledge with others, partly because it was required by their companies and partly because they have a sound awareness of the need to share knowledge both inside and outside their organizations. While compulsory knowledge sharing may be an effective way to encourage people to engage with this type of process, it is not the best method to guarantee good quality and efficient sharing of their experiences and tacit knowledge, which requires an individual and sustained effort over long periods of time.

Aware of the value of knowledge and experience as assets that need to be kept in the company in order to face the high turnover of staff that characterises the SW industry worldwide, as well as in China, managers in the case studies devised ways to encourage peers to share knowledge with their peers internally. Two of the companies studied decided to add knowledge sharing to their personal performance evaluation schemes in the form of contributions to internal information repositories. With promotions and progression in careers on the line, this was used as extrinsic motivation to prompt people's sharing, as suggested by one of the managers:

"In order to encourage them to share their experience, we ask them to post articles of shareable knowledge on our company collaborative system. These contributions are part of their performance evaluation. The evaluation depends on the volume of articles and, most importantly, the utilization of the articles by others. If people who read an article think it is good, they give feedback, such as a word or an expression picture [emoticon]. We can then assess if this is a useful article. Positive numbers of contributions, give extra scores at the end of the annual job performance evaluation." (I25.8.40.M)

However, if the knowledge sharing strategy set out by the company is not well explained and accepted by the employees, this sharing process was exposed as not being very efficient. Lack of understanding and awareness of the benefits of knowledge sharing, revealed very low levels of intrinsic motivation by the developers and a consequent poor quality of their contributions to the company information sharing system. One of the project managers explained the reasons why this knowledge sharing strategy in his company (Yirong) was a failure:

"In my opinion, the knowledge sharing strategy in my company is useless and does not really support my developers when they need it. The company requires us to contribute five tips of knowledge every season [4*3 months seasons per year]. Some of us always go to the Internet to look for some technical information to fill into the knowledge management system. Actually, there is no requirement for the content, just a request for five contributions. Even if you did not provide these five in this season, you are still allowed to compensate next season. There is no punishment. Moreover, the version of this system has not been upgraded. Some bugs are still not fixed and resolved. For example, if you import the same title with same content into the system, the system would not recognize it and still admit it as a new contribution." (I10.4.10.PM)

This quotation illustrates the misuse of a sound company strategy due to the lack of intrinsic motivation to do so. Contributions are mechanistically added that may not even be related to 
work practices due to pressure from the company. The system will then contain no real useful information and - worst - random contributions downloaded from the web rather than real contributions emerging from reflection on work practices. Therefore, even in the case of these company set structures, it is very important that individuals have intrinsic motivation to actively and voluntarily share their experiences and tacit knowledge. One of the developers believed that sharing could make him "feel pleasure" (I9.11.14.D) as follows:

"I feel very sad if there was no one answering my question [on the CoP]. So if I know the solution, I am willing to help. Moreover, some solutions are not secret or unique, and they are available in open resources on the web. If I do not contribute, the community will not work and I will have no answers in the future. So, in my opinion, if I know, I will help." (I9.11.19.D)

This intrinsic motivation as expressed by this developer shows a good awareness of the benefits belonging to a professional community of practice that enables a strong learning culture. This awareness seems to be the predominant factor in motivating knowledge sharing habits in the SW industry worldwide and in China in particular.

"In fact, sharing is a habit." (I5.14.20.M)

This simple statement by a programmer perfectly summarises the findings of this research. These findings suggest that this sharing habit results from strong intrinsic motivation that in turn is triggered by a clear awareness of the benefits associated with KS. This deceivingly simple realisation can potentially justify the failure of traditional KS strategies and the hitherto difficulties experienced in establishing $\mathrm{KM}$ as a credible organisational process. This suggests that, for KS and KM to be successful, solutions need to go beyond the established, repetitive and hitherto not very successful claims for top management support, KM champion nominations and explicit HR financial and promotion schemes.

\section{Conclusion}

This study was contextualised and grounded in the process of software development and aimed to identify factors influencing motivation for knowledge sharing (KS) in the world of practice in the software industry in China. This motivation seems to have extrinsic and intrinsic components. While the literature review in KS has extensively covered extrinsic motivation that is composed by formal policies, regulations and mechanisms offered and sometimes imposed by the organisation, the research findings indicate that the key for the success of KS seems to be related to awareness by practitioners of the benefits associated with KS. The findings also seem to indicate that the independence of the quality of KS mechanisms, top management support and well-designed policies, ultimately the key for success is also highly dependent on this awareness of individual practitioners. Therefore, the findings suggest that the focus of training and policy champions needs to be on awareness raising and less of on technical training and reward setting. Finally, although significant contributions have been proposed, the research findings presented above should be seen as a first step in the understanding of this problem area. Future work should consider further inductive research into a more rich variety of possible contexts (e,g, including SOE and larger SW companies), which could provide further insights or contrasts as determined by a good theoretical sampling practice. 


\section{Acknowledgements}

The work was supported by the National Social Science Foundation of China Major Program (Grant number: 13 \&ZD 184); the Fundamental Research Funds for the Central Universities, and the Research Funds of Renmin University of China (Grant number: 15XNLQ08); and by a "100 Talent" Seed Research Fund of the Sun Yat-sen University.

\section{References}

Abidi, S.S.R. (2007) "Healthcare knowledge sharing: purpose, practices, and prospects" in Healthcare Knowledge Management, eds. Bali, R.K. and Dwivedi, A.N. Springer, New York, pp. 67-86.

Al-Hawamdeh, S. (2003) Knowledge management: cultivating knowledge professionals, Chandos Publishing, Oxford.

Amalia, M. and Nugroho, Y. (2011) "An innovation perspective of knowledge management in a multinational subsidiary", Journal of Knowledge Management, vol. 15, no. 1, pp. 71-87.

Ambrosini, V. and Bowman, C. (2001) "Tacit knowledge: some suggestions for operationalization", Journal of Management Studies, vol. 38, no. 6, pp. 811-829.

Ardichvili, A., Maurer, M., Li, W., Wentling, T. and Stuedemann, R. (2006) "Cultural influences on knowledge sharing through online communities of practice", Journal of Knowledge Management, vol. 10, no. 1, pp. 94-107.

Awad, E.M. and Ghaziri, H.M. (2004) Knowledge management, Pearson Education International, New Jersey.

Berman, S.L., Down, J. and Hill, C.W.L. (2002) "Tacit knowledge as a source of competitive advantage in the National Basketball Association", Academy of Management Journal, vol. 45, no. 1, pp. 13-32.

Bhatt, G.D. (2002) "Management strategies for individual knowledge and organizational knowledge", Journal of Knowledge Management, vol. 6, no. 1, pp. 31-39.

Birks, M. and Mills, J. (2011) Grounded theory: a practical guide, Sage, Los Angeles.

Brown, J. and Duguid, P. (1998) "Organizing knowledge", California Management Review, vol. 40 , no. 3 , pp. $90-111$.

Cabrera, A. and Cabrera, E.F. (2002) "Knowledge-sharing dilemmas", Organization Studies, vol. 23, no. 5, pp. 687-710.

Cavusgil, T.S., Calantone, R.J. and Zhao, Y. (2003), "Tacit knowledge transfer and firm innovation capability”, Journal of Business \& Industrial Marketing, Vol. 18 No. 1, pp. 6-12.

Chen, H. (2015) Identification and Classification of Shareable Tacit Knowledge Associated with Experience in the Chinese Software Industry Sector, Degree of Doctor of Philosophy Thesis, Loughborough University, UK.

Chen, H., Baptista Nunes, J.M. and Zhou, L. (2009) "The implementation of electronic records management in facilitating knowledge sharing at software development projects", Proceedings of the 11th International Conference on Informatics and Semiotics in Organisations, Beijing, China, 11-12 April, pp. 222-231.

Chen, H., Ragsdell, G., O'Brien, A. and Nunes, M.B. (2012) "A Proposed Model of Knowledge Management in the Software Industry Sector", Proceedings of 7th International Conference on Digital Information Management (ICDIM), University of Macau, Macau, 2224 August, pp. 291-296.

Davenport, T. and Prusak, L. (1998) Working Knowledge: How Organizations Manage What They Know, Boston: Harvard Business School Press, Boston.

Dingsoyr, T. (2002) "Knowledge management in medium-sized software consulting companies", Empirical Software Engineering, vol. 7, no. 4, pp. 383-386. 
Drucker, P. (1992) "The new society of organizations", Harvard Business Review, vol. 70, no. September/October, pp. 95-105.

Edwards, J.S. (2003) "Managing software engineers and their knowledge" in Managing Software Engineering Knowledge, eds. Aurum, A., Jeffery, R., Wohlin, C. and Handzic, M. Berlin Heidelberg, Springer-Verlag, pp. 5-23.

Evers, C.W. and Wu, E.H. (2006) "On generalising from single case studies: Epistemological reflections", Journal of Philosophy of Education, vol. 40, no. 4, pp.511-526.

Fagri, T.E., Dyba, T. and Dingsoyr, T. (2010) "Introducing knowledge redundancy practice in software development: experiences with job rotation in support work", Information and Software Technology, vol. 52, pp. 1118-1132.

Gao, F., Li, M. and Clarke, S. (2008) "Knowledge, management and knowledge management in business operations", Journal of Knowledge Management, vol. 12, no. 2, pp. 3-17.

Glaser, B.G. and Strauss, A.L. (1967) The discovery of grounded theory: strategies for qualitative research, 1st ed., A Division of Transaction Publishers, New Brunswick and London.

Glaser, B.G. and Strauss, A.L. (2009) The discovery of grounded theory: strategies for qualitative research, 7th ed., Transaction Publishers, New Brunswick, USA.

Gourlay, S. (2001) "Situated cognition and knowledge: a contribution towards conceptual clarity for knowledge management", Proceedings of the 8th International Symposium on the Management of Corporate and Industrial Knowledge, Compiègne, France, 22-24 October, pp. 29-43.

Gourlay S. (2002) "Tacit knowledge, tacit knowing, or behaving?", [Online], 3rd European Organizational Knowledge, Learning, and Capabilities conference, Athens, Greece, 5-6 April. http://eprints.kingston.ac.uk/2293/1/Gourlay\%202002\%20tacit\%20knowledge.pdf.

Gourlay, S. (2006) "Towards conceptual clarity for 'tacit knowledge': a review of empirical studies", Knowledge Management Research \& Practice, no. 4, pp. 60-69.

Hansen, M.T. (1999) "The Search-transfer Problem: the Role of Weak Ties in Sharing Knowledge across Organization Sub-units", Administrative Science Quarterly, vol. 1, no. 44, pp. 82-111.

Hunter K, Hari S, Egbu C and Kelly J (2005) "Grounded Theory: Its Diversification and Application Through two Examples From Research Studies on Knowledge and Value Management", [Online], The Electronic Journal of Business Research Methodology, vol. 3, no. 1, pp. 57-68, www.ejbrm.com

Ipe, M. (2004) "Knowledge sharing in organizations: an analysis of motivators and inhibitors", Proceedings of Academy of Human Resource Development International Conference (AHRD) Austin, 3-7 March, pp. 399-406.

Jager, M. (1999) "The KMAT: benchmarking knowledge", Library Management, vol. 20, no. 7, pp. 367-372.

Jashapara, A. (2004) Knowledge management: an integrated approach, Pearson Education Limited, Harlow.

Jimes, C. and Lucardie, L. (2003) "Reconsidering the Tacit-Explicit Distinction - A Move toward Functional (Tacit)

Knowledge Management", Electronic Journal of Knowledge Management, vol. 1, no. 1, pp. 23-32.

Koskinen, K.U. (2003) "Evaluation of tacit knowledge utilization in work units", Journal of Knowledge Management, vol. 7, no. 5, pp. 67-81.

Krackhardt, D. and Hanson, J. (1993) "Informal networks: the company behind the chart", Harvard Business Review, vol. 71, no. 4, pp. 104-111.

Lam, A. (2000) "Tacit knowledge, organizational learning and societal institutions: an integrated framework", Organization Studies, vol. 21, no. 3, pp. 487-513. 
Lee, J. (2001) "The impact of knowledge sharing, organizational capability and partnership quality on IS outsourcing success", Information and Management, vol. 38, no. 5, pp. 323-335. Leonard, D. and Sensiper, S. (1998) "The role of tacit knowledge in group innovation", California Management Review, vol. 40, no. 3, pp.112-132.

Lin, H. (2007) "Effects of extrinsic and intrinsic motivation on employee knowledge sharing intentions", Journal of Information Science, vol. 33, no. 2, pp. 135-149.

Lings, B. and Lundell, B. (2005) "On the adaptation of grounded theory procedures: insights from the evolution of the $2 \mathrm{G}$ method", Information Technology and People, vol. 18, no. 3, pp. 196-211.

Mansourian, Y. (2006) "Adoption of grounded theory in LIS research", New Library World, vol. 107, no. 9/10, pp. 386-402.

McEvily, S., Das, S. and McCabe, K. (2000) "Avoiding Competence Substitution through Knowledge Sharing", The Academy of Management Review, vol. 25, no. 2, pp. 296-311.

Mishra, B. and Bhaskar, A.U. (2011) "Knowledge management process in two learning organisations", Journal of Knowledge Management, vol. 15, no. 2, pp. 344-359.

Mooradian, N. (2005) "Tacit knowledge: philosophical roots and role in KM", Journal of Knowledge Management, vol. 9, no. 6, pp. 104-113.

Nonaka, I. (1994) "A dynamic theory of organizational knowledge creation", Organization Science, vol. 5, no. 1, pp. 14-37.

Nonaka, I. (1991) "The knowledge-creating company", Harvard Business Review, vol. 69, no. 6, pp. 96-104.

Nonaka, I. and Takeuchi, H. (1995) The knowledge creating company: how Japanese companies create the dynamics of innovation, New York: Oxford University Press, New York.

Nonaka, I., Toyama, R. and Konno, N. (2000) "SECI, Ba and leadership: a unified model of dynamic knowledge creation ", Long Range Planning, vol. 33, no. 1, pp. 5-34.

Nunes, M.B., Annansingh, F., Eaglestone, B. and Wakefield, R. (2006) "Knowledge management issues in knowledge-intensive SMEs ", Journal of Documentation, vol. 62, no. 1, pp. 101-119.

Pathirage, C.A., Amaratunga, D.G. and Haigh, R.P. (2007) "Tacit knowledge and organisational performance: construction industry perspective", Journal of Knowledge Management, vol. 11, no. 1, pp. 115-126.

Patrick, K. and Dostsika, F. (2007) "Knowledge sharing: developing from within", The Learning Organization, vol. 14, no. 5, pp. 395-406.

Pauleen, D.J., Corbitt, B. and Yoong, P. (2007),"Discovering and articulating what is not yet knownUsing action learning and grounded theory as a knowledge management strategy", The Learning Organization, vol. 14, no. 3, pp. 222-240

Polanyi, M. (1958) Personal knowledge: towards a post-critical philosophy, Routledge and Kegan Paul Ltd., London.

Polanyi, M. (1966) The tacit dimension, Routledge and Kegan Paul Ltd., London.

Renzl, B., Matzler, K. and Hinterhuber, H.H. (2005) The future of knowledge management, Antony Rowe Ltd., Great Britain.

Riege, A. (2005),"Three-dozen knowledge-sharing barriers managers must consider", Journal of Knowledge Management, vol. 9, no. 3, pp. 18-35.

Riege, A. (2007),"Actions to overcome knowledge transfer barriers in MNCs", Journal of Knowledge Management, vol. 11, no. 1, pp. 48-67.

Rodhain, F. (1999) " Tacit to explicit: transforming knowledge through cognitive mappingan experiment", Proceedings of the 1999 ACM SIGCPR conference on Computer personnel research ACM, New York, NY, USA, 1 April, pp. 51-56. 
Ryu, S., Hee, H.S. and Han, I. (2003) "Knowledge sharing behaviour of physicians in hospitals", Expert Systems with application, vol. 25, pp. 113-122.

Sackmann, S.A. and Friesl, M. (2007) "Exploring cultural impacts on knowledge sharing behaviour in project teams - results from a simulation study", Journal of Knowledge Management, vol. 11, no. 6, pp. 142-156.

Sternberg, R.J. (1994) "Tacit knowledge and job success" in Assessment and Selection in Organizations: Methods and Practice for Recruitment and Appraisal, eds. Anderson, P. John Wiley, London, pp. 27-39.

Strauss, A. and Corbin, J. (1998) Basics of qualitative research: techniques and procedures for developing Grounded Theory (2nd ed), Sage, Thousand Oaks, CA.

Suppiah, V. and Sandhu, M.S. (2011) "Organisational culture's influence on tacit knowledgesharing behaviour", Journal of Knowledge Management, vol. 15, no. 3, pp. 462-477.

Taft, D.K. (2012) "Chinese Software Industry to Grow 25\% Through 2016 Report ", [Online], 1 September 2012, http://www.eweek.com/c/a/Application-Development/Chinese-SoftwareIndustry-to-Grow-25-Through-2016-Report-605295.

Venkitachalam, K. and Busch, P. (2012) "Tacit knowledge: review and possible research directions", Journal of Knowledge Management, vol. 16, no. 2, pp.357-372.

Wilson, T.D. (2002) "The nonsense of 'knowledge management"', [Online], Information Research, vol. 8, no. 1. http://informationr.net/ir/8-1/paper144.html.

Yang, L. (2011) "China's software industry revenue up 31.4\% in July", [Online], 24 August 2011, http://english.gov.cn/2011-08/24/content 1931961.htm.

Zhou, L. and Nunes, J.M. (2012) "Identifying Knowledge Sharing Barriers in the Collaboration of Traditional and Western Medicine Professionals in Chinese Hospitals: A Case Study", Journal of Librarianship and Information Science, vol. 44, no. 4, pp. 238-248.

Zhou, L. and Nunes, M.B. (2016) "Barriers to knowledge sharing in Chinese healthcare referral services: an emergent theoretical model", Global health action, vol. 9, no. 1, pp.29964. 


\section{Appendix. Biographical Profile of Participants}

\begin{tabular}{|c|c|c|c|c|c|c|c|c|}
\hline Interviewee & & Job Title & Identifier & Age & Gender & $\begin{array}{l}\text { Years of IT } \\
\text { work } \\
\text { Experience } \\
\text { (at the } \\
\text { moment of } \\
\text { interview - } \\
\text { 2016) }\end{array}$ & $\begin{array}{l}\text { Duration } \\
\text { (h:m:s) }\end{array}$ & $\begin{array}{l}\text { Number of } \\
\text { Transcribed } \\
\text { Words }\end{array}$ \\
\hline \multirow{6}{*}{$\begin{array}{l}\text { SME } \\
\text { (Baidu } \\
\text { chuan) }\end{array}$} & Interview 1 & Project Manager & $\mathrm{PM}$ & $30-34$ & $\mathrm{M}$ & 10 & 2:01:01 & 15,930 \\
\hline & Interview 2 & $\begin{array}{l}\text { Product Manager } \\
\text { and Designer }\end{array}$ & $\mathrm{D}$ & $25-29$ & $M$ & 5 & $1: 20: 03$ & 12,154 \\
\hline & Interview 3 & $\begin{array}{l}\text { Web Editor } \\
\text { /Content Manager }\end{array}$ & $\mathrm{D}$ & $25-29$ & $\mathrm{~F}$ & 2 & $1: 29: 20$ & 15,098 \\
\hline & Interview 4 & Vice Manager & $\mathrm{M}$ & $35-39$ & $\mathrm{M}$ & 10 & 1:11:43 & 16,008 \\
\hline & Interview 5 & Vice Manager & $\mathrm{M}$ & $40-44$ & $\mathrm{M}$ & 20 & $1: 16: 00$ & 14,628 \\
\hline & Interview 6 & Developer & $\mathrm{D}$ & $25-29$ & $\mathrm{M}$ & 3 & $1: 14: 46$ & 13,368 \\
\hline \multirow{13}{*}{$\begin{array}{l}\text { SOE } \\
\text { (YiRong ) }\end{array}$} & Interview 7 & Installation Expert & $\mathrm{D}$ & $25-29$ & $\mathrm{M}$ & 5 & 1:03:19 & 13,112 \\
\hline & Interview 8 & Installation Expert & $\mathrm{D}$ & $30-34$ & $\mathrm{M}$ & 8 & $0: 37: 22$ & 7,530 \\
\hline & Interview 9 & Installation Expert & $\mathrm{D}$ & $20-24$ & $\mathrm{M}$ & 2 & $0: 46: 45$ & 8.902 \\
\hline & Interview 10 & $\begin{array}{l}\text { Installation Expert } \\
\text {-Team Leader }\end{array}$ & PM & $30-34$ & $M$ & 7 & $1: 07: 45$ & 12,716 \\
\hline & Interview 11 & Project Manager & PM & $35-39$ & $\mathrm{M}$ & 10 & $1: 23: 28$ & 13,470 \\
\hline & Interview 12 & $\begin{array}{l}\text { Senior R\&D } \\
\text { Engineer }\end{array}$ & $\mathrm{D}$ & $35-39$ & $\mathrm{M}$ & 11 & $0: 47: 49$ & 10,257 \\
\hline & Interview 13 & $\begin{array}{l}\text { Technical } \\
\text { Supporter }\end{array}$ & $\mathrm{D}$ & $30-34$ & $\mathrm{M}$ & 6 & 1:03:07 & 10,330 \\
\hline & Interview 14 & Senior R\&D & $\mathrm{D}$ & $30-34$ & $\mathrm{M}$ & 8 & $0: 25: 09$ & 5,411 \\
\hline & Interview 15 & R\&D Engineer & $\mathrm{D}$ & $20-24$ & $\mathrm{M}$ & 2 & $0: 22: 19$ & 4,858 \\
\hline & Interview 16 & SW Engineer & D & $30-34$ & $\mathrm{M}$ & 5 & $0: 18: 57$ & 3,280 \\
\hline & Interview 17 & Java Developer & $\mathrm{D}$ & $20-24$ & $\mathrm{~F}$ & 3 & $0: 30: 31$ & 6,097 \\
\hline & Interview 18 & R \& D Manager & $\mathrm{PM}$ & $35-39$ & $\mathrm{M}$ & 14 & $0: 27: 51$ & 4,594 \\
\hline & Interview 19 & $\begin{array}{l}\text { Department } \\
\text { Manager }\end{array}$ & $\mathrm{M}$ & $35-39$ & $\mathrm{M}$ & 10 & $1: 05: 56$ & 14,129 \\
\hline \multirow{22}{*}{$\begin{array}{l}\text { Large } \\
\text { Private } \\
\text { (Bosi) }\end{array}$} & Interview 20 & Installation Expert & $\mathrm{D}$ & $20-24$ & $\mathrm{~F}$ & 2 & 1:05:50 & 16,702 \\
\hline & Interview 21 & Installation Expert & $\mathrm{D}$ & $20-24$ & $\mathrm{M}$ & 1 & $1: 04: 53$ & 8,878 \\
\hline & Interview 22 & Installation Expert & $\mathrm{D}$ & $20-24$ & $\mathrm{M}$ & 1 & $0: 23: 23$ & 3,249 \\
\hline & Interview 23 & $\begin{array}{l}\text { Installation } \\
\text { Expert-Team } \\
\text { Manager } \\
\end{array}$ & PM & $35-39$ & $\mathrm{M}$ & 9 & $1: 31: 37$ & 18,459 \\
\hline & Interview 24 & Installation Expert & $\mathrm{D}$ & $30-34$ & $\mathrm{M}$ & 6 & 1:19:53 & 17,793 \\
\hline & Interview 25 & $\begin{array}{l}\text { SG Project } \\
\text { Department } \\
\text { Manager }\end{array}$ & $\mathrm{M}$ & $35-39$ & M & 15 & $2: 09: 15$ & 30,989 \\
\hline & Interview 26 & $\begin{array}{l}\text { Development } \\
\text { Manager }\end{array}$ & PM & $30-34$ & $\mathrm{M}$ & 8 & $1: 34: 42$ & 18,231 \\
\hline & Interview 27 & $\begin{array}{l}\text { Installation } \\
\text { Manager }\end{array}$ & PM & $35-39$ & $\mathrm{M}$ & 14 & $1: 52: 52$ & 23,029 \\
\hline & Interview 28 & $\begin{array}{l}\text { Installation } \\
\text { Manager }\end{array}$ & PM & $30-34$ & $\mathrm{M}$ & 7 & $1: 14: 29$ & 16,410 \\
\hline & Interview 29 & R\&D Developer & $\mathrm{D}$ & $25-29$ & $\mathrm{M}$ & 4 & $0: 31: 17$ & 6,061 \\
\hline & Interview 30 & $\begin{array}{l}\text { R\&D Team } \\
\text { Leader }\end{array}$ & $\mathrm{D}$ & $25-29$ & $\mathrm{~F}$ & 5 & $1: 05: 25$ & 10,986 \\
\hline & Interview 31 & SW Programmer & $\mathrm{D}$ & $25-29$ & $\mathrm{M}$ & 3 & $0: 43: 54$ & 7,917 \\
\hline & Interview 32 & $\begin{array}{l}\text { Development } \\
\text { Manager } \\
\text {-Team Leader }\end{array}$ & PM & $35-39$ & $\mathrm{M}$ & 12 & $1: 06: 18$ & 14,276 \\
\hline & Interview 33 & $\begin{array}{l}\text { Installation } \\
\text { Experts } \\
\end{array}$ & $\mathrm{D}$ & $25-29$ & $\mathrm{M}$ & 1 & $1: 04: 32$ & 10,184 \\
\hline & Interview 34 & $\begin{array}{l}\text { Development } \\
\text { Manager }\end{array}$ & PM & $25-29$ & $\mathrm{M}$ & 5 & $1: 24: 36$ & 13,722 \\
\hline & Interview 35 & Programmer & $\mathrm{D}$ & $20-24$ & $\mathrm{M}$ & 2 & 1:09:29 & 12,102 \\
\hline & Interview 36 & Developer & $\mathrm{D}$ & $20-24$ & $\mathrm{M}$ & 2 & $0: 37: 14$ & 6,420 \\
\hline & Interview 37 & $\begin{array}{l}\text { Java } \\
\text { Development } \\
\text { Engineer } \\
\end{array}$ & $\mathrm{D}$ & $20-24$ & $\mathrm{M}$ & 1 & $0: 31: 36$ & 5,327 \\
\hline & Interview 38 & Tester & $\mathrm{T}$ & $30-34$ & $\mathrm{~F}$ & 8 & $1: 04: 46$ & 10,753 \\
\hline & Interview 39 & $\begin{array}{l}\text { Product } \\
\text { Department } \\
\text { Manager }\end{array}$ & $\mathrm{M}$ & $30-34$ & $\mathrm{M}$ & 5 & $1: 15: 26$ & 14,245 \\
\hline & Interview 40 & Installation Expert & $\mathrm{D}$ & $20-24$ & $\mathrm{M}$ & 1 & 1:15:59 & 11,256 \\
\hline & Interview 41 & $\begin{array}{l}\text { Development } \\
\text { Manager } \\
\text {-Team Leader }\end{array}$ & PM & $25-29$ & $M$ & 3 & $1: 28: 49$ & 12,378 \\
\hline
\end{tabular}




\begin{tabular}{|l|l|l|c|c|c|c|c|c|}
\hline \multirow{2}{*}{4} & Interview 42 & $\begin{array}{l}\text { Owner/Share } \\
\text { Holder }\end{array}$ & SH & $40-44$ & M & 15 & $1: 16: 55$ & 12,867 \\
\cline { 2 - 10 } & Interview 43 & Sales Manager & S & $30-34$ & M & 12 & $0: 35: 30$ & 7,093 \\
\cline { 2 - 10 } & Interview 44 & $\begin{array}{l}\text { Human } \\
\text { Resources }\end{array}$ & HR & $30-34$ & F & 6 & $0: 04: 10$ & 890 \\
\hline
\end{tabular}

14

15

16

17

19

20

21

24

25

26

27

29

30

31

32

33

34

35

36

39

40

41

42

46

47

48

49

50

51

56

57

(7)

18

